\title{
External Radiation at a Full Scale Fire Experiment
}

\author{
ISAO TSUKAGOSHI and EIICHI ITOIGAWA \\ Building Research Institute \\ Oho, Tsukuba, Ibaraki 305 Japan
}

\begin{abstract}
For the vast wooden house built-up areas in Japanese cities, Firebreak Belts (F.B.B.) are thought practical and effective against a post-earthquake urban fire. When a wooden house area is guarded by a vertical type of F.B.B. such as elevated traffic ways, a row of fireproof buildings, etc., this area might be exposed to the radiation mainly from the upper part of flame. The existing calculation method which assumes the homogeneous distribution within an imaginary plane of heat source should be reconsidered and the difference between upper and lower parts of flame in raqiation intensity must be discussed theoretically and empirically. In this paper, after the descriptions on the background and purpose of study, the outline of a full scale fire experiment are explained and the data of its external radiation are analyzed. Finally, a calculation model of the radiation from a big urban fire is proposed for the evaluation of effect of F.B.B..
\end{abstract}

\section{INTRODUCTION}

\section{Background of Study}

Major Japanese cities such as Tokyo and Osaka are quite vulnerable to urban fires because of the existence of a great number of combustible buildings. Specially in case of a great earthquake, this condition of urban area might cause the wide spread of multiple and simultaneous fires, which will grow up into a great urban fire as sizable as a whole built up area.

In order to cope with this problem, a system of Urban Fire Prevention Units is proposed. (Outline of the system is introduced in Ref. 3) The basic concept of this system is the compartmentalization of a vast combustible area, being divided into a number of small combustible zones by means of a effective allocation of linear non-combustible zones called Firebreak Belt (F.B.B.). The realization of this system would require a specific urban planning and some administrative institutions and, at the same time, it is quite necessary to establish a practical design method for F.B.B. including a quantitative evaluation method for effect of F.B.B..

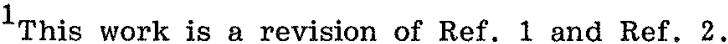




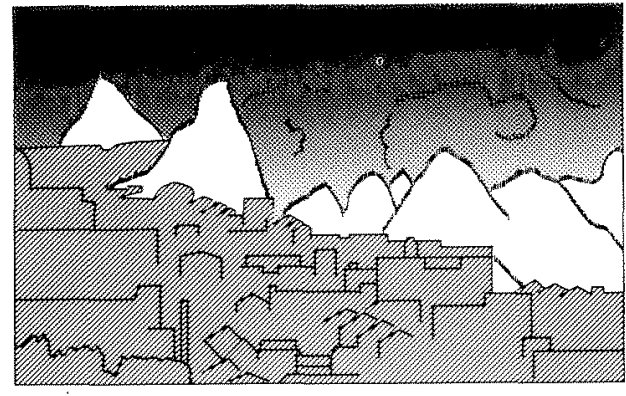

Figure 1. Shizuoka big fire (reproduced by the author from the ilustration in Ref. 5.)

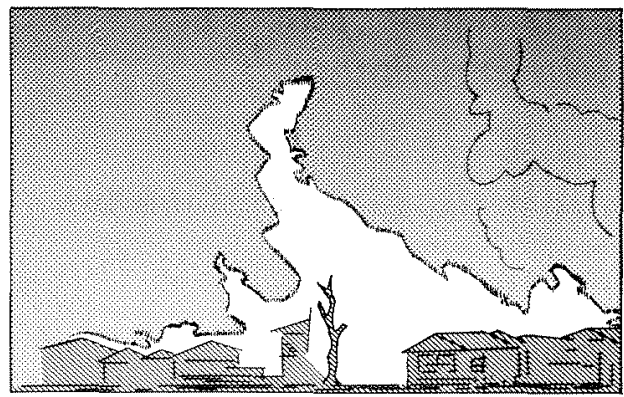

Figure 2. Ohdate big fire (reproduced by the auther from the photo in Ref. 6.)

\section{Shape of Urban Fire Flame}

To evaluate practically the effect of F.B.B. against an urban fire, it is necessary to estimate the radiation intensity from a big merged flame by means of a simplified model of complicated shapes of flames. In the Ref. 4 , Dr. Hamada has proposed a model of radiation source as a rectangular plane inclined downwind and regarded the radiation distribution within this plane as homogeneous.

There are two types of F.B.B.; one composed of flat elements like surface traffic ways, flat open spaces, etc., and the other the combination of vertical elements such as elevated traffic ways, densely planted trees and a row of fire proof buildings.

The radiation received behind the flat type of F.B.B. can be calculated almost correctly even through the model of homogeneous heat source since a heat receiving point is facing against the whole plane of heat source. In case of vertical type, however, this method is not necessarily reasonable because the vertical walls interrupt the radiation from the lower part of flame and only the upper part of flame above the walls is important. Therefore, we must discuss the distribution of radiation to the vertical direction along the surface of flame.

An urban scale fire is different from ordinary fire mainly in its size of flame. The height of flame for a two storied wooden house is approximately 15 meters in the maximum, but in case of an urban scale big fire, it is believed to become much higher with the effect of merge of flames.

Figure 1. and 2. show the shapes of flames at the Shizuoka big fire in 1940 and at the Ohodate big fire in 1955 respectively. They indicate that the flames of urban scale fire are shaped like a series of pyramids. For this kind of shape, the heat source plane can be assumed as multiple triangles, but this assumption leads to a meaningless complication at the calculation of the view factor. (See Figure 3.) So that, we have assumed, like Hamada's method, a rectangular plane where the radiation intensity depends upon the vertical coordinate of heat source. The flame shape illustrated in Figure 3 . makes us anticipate a linear reduction of heat flux according to the height of heat source. To verify this relation quantitatively, a full scale fire experiment was executed. 
A. existing method; assuming the uniform distribution of radiation within a imaginary plane average intensity

$$
\mathrm{R}=0.5 \mathrm{E}
$$

B. proposed method; uniform distribution only within a horizontal stripe. average intensity

$$
R=(1-h / H) E
$$
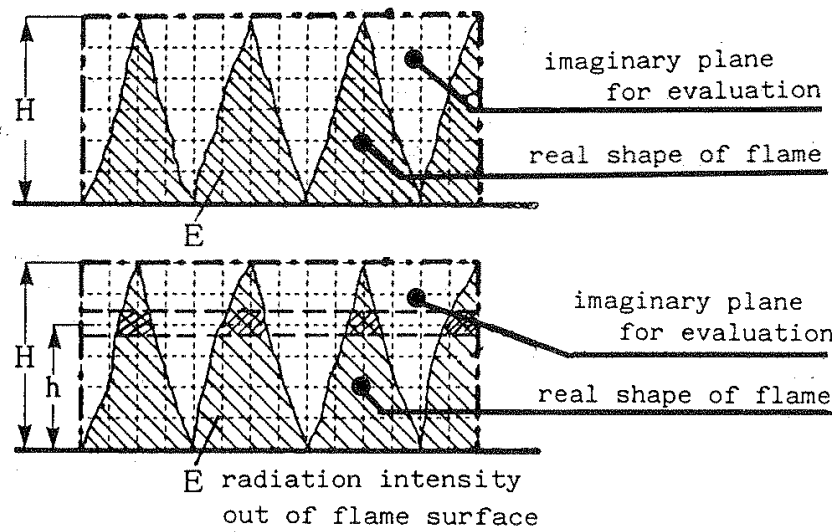

Figure 3. Real shape of flame and imaginary plane of heat source

\section{EXPERIMENT}

\section{Outline of Experiment}

For the purpose of this study, it was quite desirable to realize the simultaneous burning of a group of houses but in view of the safety condition of experiment it was difficult. And among the aborted buildings in the Tachikawa base of U.S.army, a two storied wooden house for four families were selected as the object of experiment. The outline of this building is shown in Table 1. and in Figure 4. and other conditions of the experiment are indicated in Table 2..

The experiment was performed on October 1st in 1980. In order to get a maximum size of flame, the burning were initiated at the four points indicated in Figure 5, using four wooden cribs, under the condition of all the windows

Table 1. Outline of test building

$\begin{array}{ll}\text { place } & \begin{array}{l}\text { natl. park of Syouwa-Kinen } \\ \text { Kohen, Tachikawa, Tokyo; }\end{array} \\ \text { use } & \begin{array}{l}\text { residential } \\ \text { floor }\end{array} \\ \text { area } & \begin{array}{l}\text { ground fl. } 334.48 \mathrm{~m}_{2}^{2} \\ \text { total fl. } 428.01 \mathrm{~m}^{2}\end{array} \\ \text { structure } & \text { wooden; partly } 2 \text { storied } \\ \text { roof } & \text { asbestos cement roof tile } \\ \text { ext.wall } & \text { mortal and paint } \\ \text { ceiling } & \text { plaster bd. and paint } \\ \text { partition } & \text { plaster bd. and paint } \\ \text { floor } & \text { p.v.c. tile }\end{array}$

\begin{tabular}{|c|c|}
\hline $\begin{array}{l}\text { date } \\
\text { climate }\end{array}$ & $\begin{array}{l}\text { Oct. } 1,1980,11: 00 \\
\text { fair, } 23^{\circ} \mathrm{c}, 42{ }^{\circ}, \\
\text { av. wind } 2.7 \mathrm{~m} / \mathrm{s} \mathrm{N}-\mathrm{NE}\end{array}$ \\
\hline $\begin{array}{l}\text { loaded } \\
\text { combust. }\end{array}$ & $\begin{array}{l}\text { timber of destructed house } \\
57 \mathrm{~kg} / \mathrm{m} \text { uniformly set on } \\
\text { the floor, (water } 23.3 \% \text { ) } \\
\text { (fixed load } 143 \mathrm{~kg} / \mathrm{fl} . \mathrm{m}^{2} \text { ) }\end{array}$ \\
\hline & $\begin{array}{l}200 \mathrm{~kg} / \mathrm{m}_{2}^{2} \text { per total } \mathrm{fl} . \\
256 \mathrm{~kg} / \mathrm{m}^{2} \text { per ground } \mathrm{fl} .\end{array}$ \\
\hline nit. & $\begin{array}{l}4 \text { points same time at the } \\
\text { north entrances, using } \\
\text { wood crib }\end{array}$ \\
\hline $\begin{array}{l}\text { Adows } \\
\text { doors }\end{array}$ & all opened to the full \\
\hline
\end{tabular}

Table 2. Experiment condition 


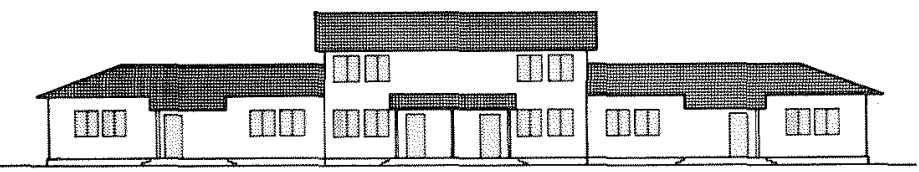

SOUTH

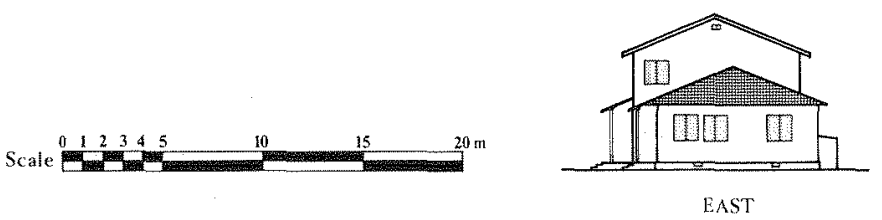

Figure 4. South and east side views of test building

and doors remained open. Immediately after ignition, the fires were fully developed all over the initial rooms. About three minutes after, they reached to the all the rooms on the ground floor and 10 or 11 minutes later through the staircases to the second floor. After the roof of the second floor was broken (about 20 minutes after ignition), the heights of flames became higher as is shown in Figure 6.

\section{Observation Method}

Following equipments were used for the observation in regard to the radiation;
1. Thermoviewer (Infrared thermometer)
2. Video camera
3. Radiation meter
$\mathrm{x} 1$,
$\times 2$,
$\mathrm{x} 4$.

Measuring conditions of the equipments are shown in Table 3 , and the allocation of them in Figure 5 .

Table 3. Measuring condition

\begin{tabular}{|c|c|c|}
\hline $\begin{array}{l}\text { equipment } \\
\text { \& type }\end{array}$ & $\begin{array}{l}\text { record } \\
\text { interval }\end{array}$ & $\begin{array}{l}\text { recording } \\
\text { method }\end{array}$ \\
\hline $\begin{array}{l}\text { thermoviewer } \\
\text { (Nihon Densi } \\
\text { co.Itd.) }\end{array}$ & $1 \mathrm{sec}$ & $\begin{array}{l}\text { on } 1 / 2^{\prime \prime} \text { video } \\
\text { tape by Sony } \\
\text { SLO-330. }\end{array}$ \\
\hline $\begin{array}{l}\text { video camera } \\
\text { (Sony DXC- } \\
2000 \text { ) }\end{array}$ & $1 / 30 \mathrm{sec}$ & $\begin{array}{l}\text { NTSC composite } \\
\text { signal on } 3 / 4^{\prime \prime} \\
\text { tape by Sony } \\
\text { VO- } 2950\end{array}$ \\
\hline $\begin{array}{l}\text { radiation- } \\
\text { meter }\end{array}$ & $\begin{array}{l}30 \text { sec } \\
(\mathrm{R} 1, \mathrm{R} 4) \\
120 \mathrm{sec} \\
(\mathrm{R} 2, \mathrm{R} 3)\end{array}$ & $\begin{array}{l}\text { YODAC thermal } \\
\text { recorder } \\
\text { (Yokokawa } \\
\text { Denki co,Itd) }\end{array}$ \\
\hline
\end{tabular}

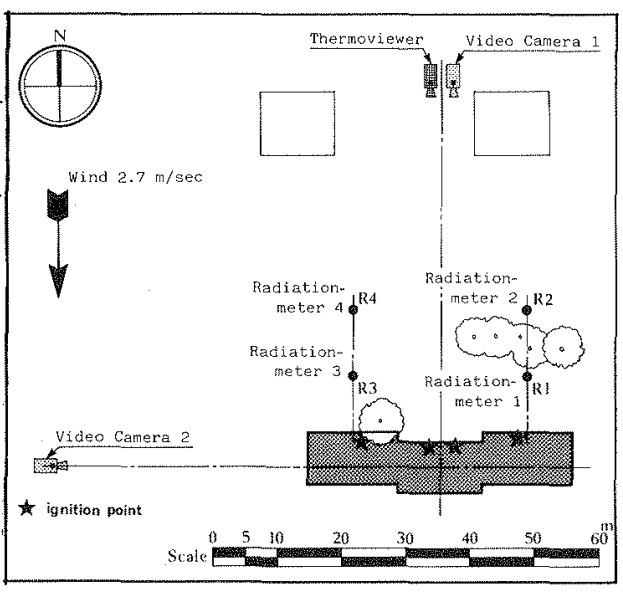

Figure 5. Location of equipments 


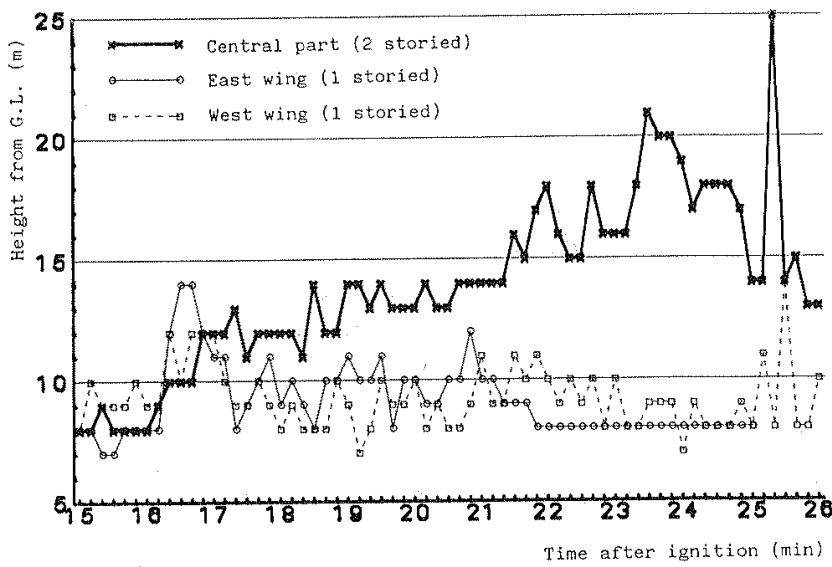

Figure 6. Time history of flame height

With a scanning system, the thermoviewer has a function to output the temperature distribution of the object whose emissivity can be considered the same as the setting value on the equipment. In this case, the emissivity was set up to 1.0. Therefore, the indicated value for the object of low emissivity doesn't mean the exact value of temperature but it corresponds to the intensity of radiation flux including the effect of emissivity.

Time History of Flame Height and Radiation

The time histories of the maximum flame heights (above the ground level) for the one and two story parts were obtained with two video cameras as are shown in Figure 6.. From these data, it can be known that the most active burning period for the two story part would be from 23 to 25 minutes after ignition. Figure 7 . is the time histories of radiation intensities observed at four radiation meters and shows the most active burning period from 21 to 23

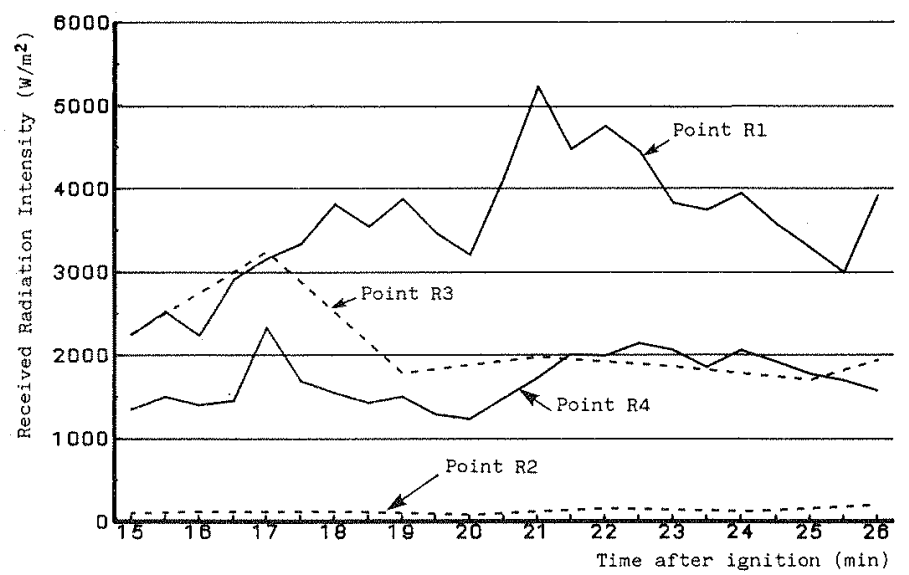

Figure 7. Time history of radiation intensity at $R 1-R 4$ 


$$
\begin{aligned}
& \square \text { under } 200^{\circ} \mathrm{c} \\
& 200-300^{\circ} \mathrm{c} \\
& 300-400^{\circ} \mathrm{c} \\
& 400-500^{\circ} \mathrm{C} \\
& 500-600^{\circ} \mathrm{c} \\
& 600-700^{\circ} \mathrm{c} \\
& 700-800^{\circ} \mathrm{c} \\
& 800-900^{\circ} \mathrm{c} \\
& 900-1000^{\circ} \mathrm{c} \\
& 1000^{\circ} \mathrm{c} \text { over }
\end{aligned}
$$

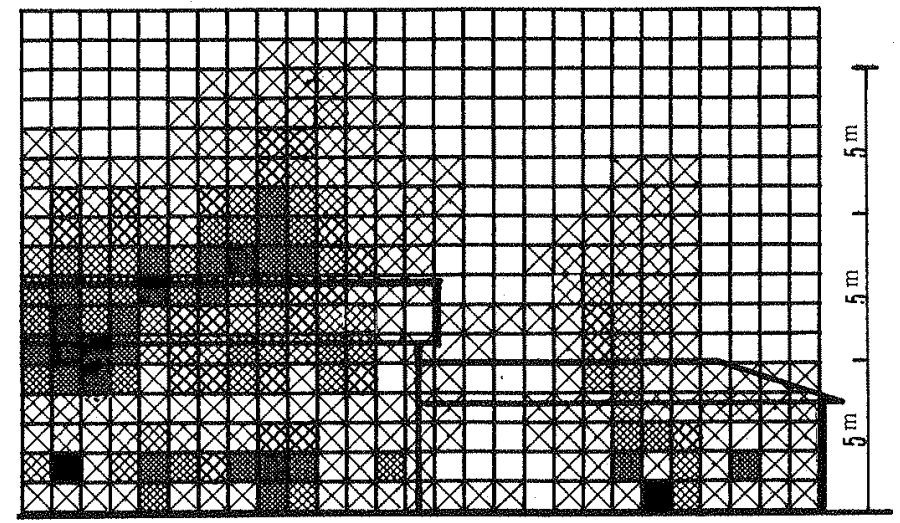

Figure 8 . Distribution of average temperature from 21 to $25 \mathrm{~min}$. after ignition

minutes. After all, we have judged that the most active and stable burning period of this experiment was from 21 to 25 minutes after ignition.

\section{ANALYSES}

Distribution of Radiation Intensity

The thermoviewer analogue data recorded on a magnetic tape were processed to digital data in accordance with the divided meshes (one meter square for each) on the vertical plane assumed at the north side of the building. Processing time interval was every 30 minutes.

With these data, an average temperature for each mesh can be calculated according to the following formula;

$\mathrm{T}_{\mathrm{ij}}=\sqrt[4]{\mathrm{T}_{\mathrm{ijt}}{ }^{4} / \mathrm{p}}$

where $\quad T_{i j}$ : average temperature for mesh $(i, j) \quad(K)$

$$
\begin{array}{ll}
\mathrm{T}_{\mathrm{ijt}} & \text { : observed temperature for mesh }(i, j) \text { at time } t \\
\mathrm{p} & : \text { number of data for a mesh }(t=1 \text { to } p) \\
\mathrm{i} & : \text { horizontal position of mesh }(i=1 \text { to } m) \\
j & \text {; vertical position of mesh }(j=1 \text { to } n) .
\end{array}
$$

Figure 8 . is the illustration of average temperatures $\left({ }^{\mathrm{T}} \mathrm{ij}\right)$ in the period from 21 to 25 minutes. Within the plane of heat source, the difference of temperature might be caused by the fluctuations of the flame shape above the roof line and by the allocation of openings on solid mortal walls below the roof line. However, we can recognize a total tendency that the average value of temperature in the upper part is less than in the lower part.

\section{Comparison between Observed and Estimated Radiation}

For the validation of the function of thermoviewer, estimated radiation values corresponding to the thermoviewer temperature were compared with the 


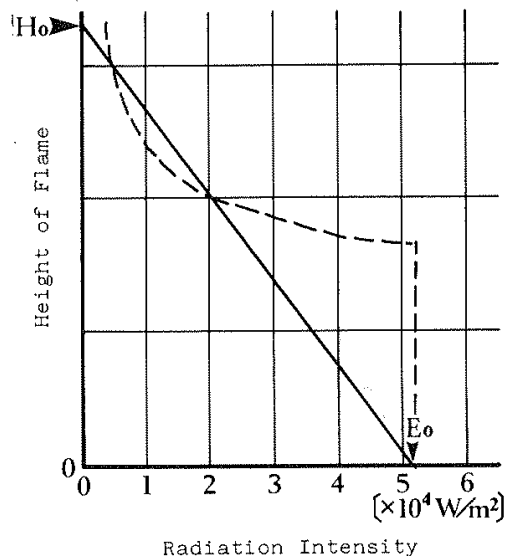

Figure 11. Simplified profile of radiation on a heat source plane

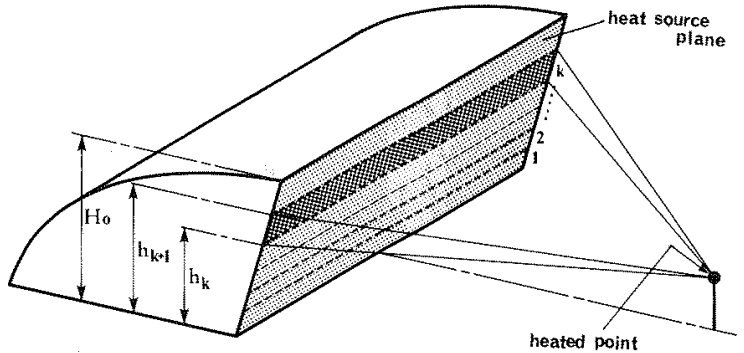

Figure 12. Heat source for calculation of radiation

$R_{i j}=f_{i j} \cdot s \cdot T_{i j}{ }^{4}$

where $\mathrm{T}_{\text {ot }}$ in the formula (3) is relatively small and has been neglected.

\section{Vertical Profile of Radiation}

An average value of different radiation intensities for the same vertical position of a heat source mesh was calculated by the following formulae;

$E_{j}=\left(\sum_{i} \sum_{t} E_{i j t}\right) /(p \cdot m)$

$E_{i j t}=s \cdot\left(T_{i j t}\right) 4$

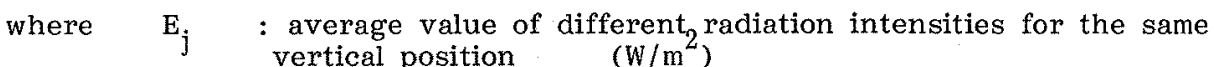

$\mathrm{E}_{\mathrm{ijt}}$ : radiation intensity for mesh $(i, j)$ at time $\mathrm{t}\left(\mathrm{W} / \mathrm{m}^{2}\right)$

With the observed data for the two story part, the vertical profile of radiation was calculated and is indicated in Figure 10. It is clear that above the roof line, the average radiation decreases according to the increase in the height of a heat source. Below the roof line, however, the large scatter in radiation flux has been caused by the influence of the openings located on the solid mortal wall.

\section{CONCLUSION}

If the results of this experiment can be generalized, the dotted line in Figure 11. should be proposed as a model of vertical profile in radiation flux. However, to adopt this model for an actual urban area, this must be well confirmed through other validation studies; for different constructions of building and for different fire conditions. 


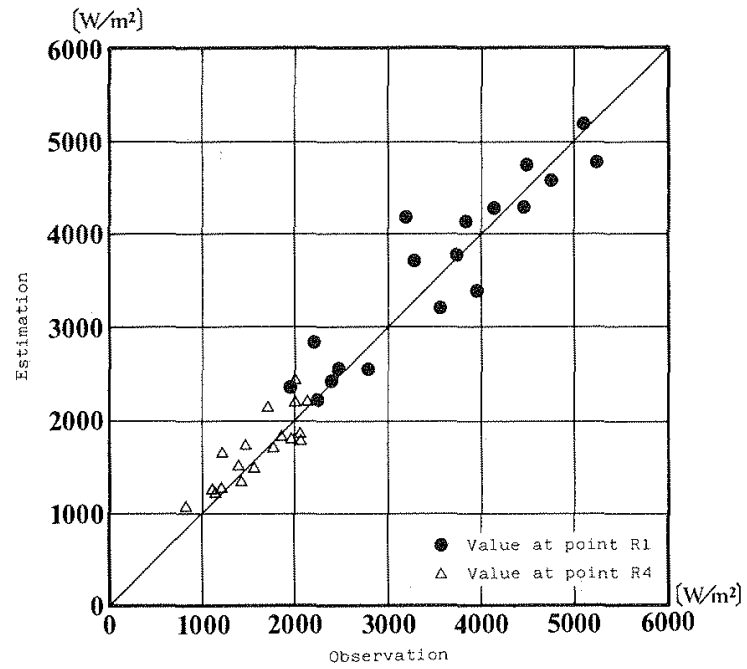

Figure 9. Comparison of observed \& estimated radiations

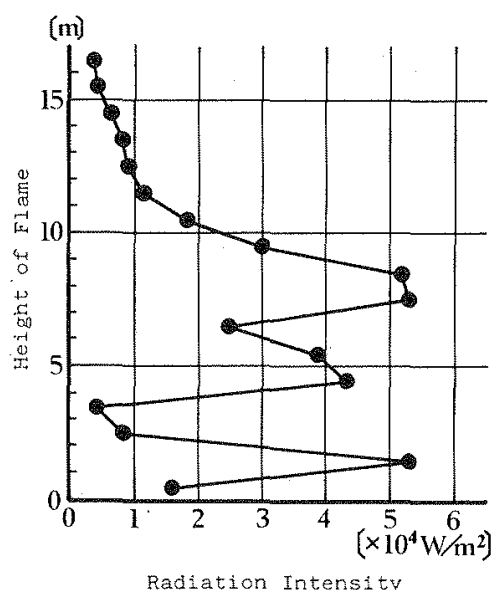

Figure 10. Vertical profile of radiation on the flame

actual radiation values measured by the radiation meters of $R 1$ and $R 4$. The method of estimation is as follows;

$R_{\text {ot }}=\underset{i j}{i j} R_{i j t}$

$R_{i j t}=f_{i j} \cdot e_{i j} \cdot s \cdot\left(T_{i j t}{ }^{4}-T_{o t}{ }^{4}\right)$

where $\quad R_{\text {ot }}$ : total radiation at receiving point at time $t \quad\left(\mathrm{~W} / \mathrm{m}^{2}\right)$

$\mathrm{R}_{\mathrm{ljt}}$ : radiation flux from mesh $(i, j)$ at time $t\left(W / \mathrm{m}^{2}\right)$

$f_{i j}$ : view factor between mesh $(i, j)$ and a receiving point (-)

$e_{i j} \quad$ : (emissivity for mesh $(i, j)$ ) x(absorptivity for a receiving point) (-)

s: : constant of Stefan Boltzmann $5.67 \times 10^{-8}\left(\mathrm{~W} / \mathrm{m}^{2} / \mathrm{K}^{4}\right)$

$\mathrm{T}_{\text {ot }}$ : temperature at a receiving point at time $\mathrm{t}(\mathrm{K})$

The observed and estimated values of received radiation at the positions of radiation meters $R 1$ and $R 4$ are plotted on Figure 9 , where $f_{i j}$ can be calculated by the geometric relation between heat source meshes and a heat receiving point, and $e_{i j}$ can be assumed as 1.0 because the emissivity of a flame is included in the observed value of temperature as the thermoviewer's function which has been explained in the previous section. Under these conditions, a good correlation between two values has been obtained as is shown in Figure 9 .

Therefore, the thermoviewer is allowed to work as a kind of scanning radiation meter, instead of a thermometer and for this purpose, only the conversion of data by the next formula is required; 
So that, in this stage of study, we can only propose, as the simplest model which will present the overall tendency, a linear profile like the solid line in Figure 11.

This linear model can be described as follows (see Figure 12.);

$\mathrm{R}_{\mathrm{k}} \fallingdotseq \mathrm{f}_{\mathrm{k}} \cdot \mathrm{E}_{\mathrm{o}} \cdot\left(1-\left(\mathrm{h}_{\mathrm{k}}+\mathrm{h}_{\mathrm{k}+1}\right) / 2 \mathrm{H}_{\mathrm{o}}\right)$

where $\quad R_{k}$ : radiation from the $\mathrm{k}$-th horizontal stripe $\left(\mathrm{W} / \mathrm{m}^{2}\right)$

$\mathrm{f}_{\mathrm{k}}$ : view factor for the $\mathrm{k}$-th horizontal stripe (-)

$\mathrm{E}_{\mathrm{O}}$ : maximum radiation intensity $=5.12 \times 10^{4}\left(\mathrm{~W} / \mathrm{m}^{2}\right)$

$h_{k}$ : height of lower bound of the $k$-th stripe

$h_{k+1}$ : height of upper bound of the $k$-th stripe

$\mathrm{H}_{\mathrm{O}}$ : height of flame (L)

k ; vertical position of horizontal stripe on heat source plane.

Predicted value for the radiation below the roof line might be different to some extent from the actual value but, when the model is applied to the large flame in an urban fire, the difference would become relatively small. For a design of flat type of firebreak, only the total amount of radiation flux is important and for a vertical type of firebreak, the radiation out of the heat source below the roof line could be concealed.

With these reasons, we have determined to adopt the simple linear model for a design of firebreak but, for a more strict argument, additional experiments and further studies are necessary.

\section{REFERENCE}

1. Itoigawa, E., Tsukagoshi, I. : "Distribution of Radiation Intensity along the Vertical Direction of Flame (Estimation of Radiation Intensity in case of Seismic City Fire, part 1)"; Summaries of Technical Papers on Annual Meetings of Architectural Institute of Japan, Sept.,1983.

2. Tsukagoshi, I., Itoigawa,E. : "Evaluation of Fire Blocking Belt in the Planning of Urban Fire Prevention Unit, part 1 Estimation of fire load to fire blocking belt" : Transaction of Architectural Institute of Japan, No. 340 June 1984 .

3. Tsukagoshi, I., Tanahashi, I., Itoigawa, E., Iwakawa, N., Kumagai, Y., Murosaki, M, Ogawa, Y., Sato, T : "A STudy on Urban Fire Prevention in case of Big Earthquake" : 8th World Conference on Earthquake Engineering - San Francisco, July 1984.

4. Hamada, M., Suzuki, Y. : "Taishin Kasai-ji no Shoushitu han-i no Suikei" (Prediction for burning area in case of post-earthquake urban fire) : Summaries of Technical Papers on Annual Meetings of Architectural Institute of Japan, 1633-1636, Sept. 1974 .

5. Fujita, K.: "Fire spread caused by radiation and its prevention" in Kasai no Kenkyuu, Sagami-Shoboh, Tokyo, 1951.

6. Kamei, K. : "A report on Ohdate big fire" in Journal of Japanese Association of Fire Science and Engineering, vol.3. 127, 1955. 
